\title{
Domestic Cooking Effects of Bambara Groundnuts and Common Beans in the Antioxidant Properties and Polyphenol Profiles
}

\author{
V. Nyau ${ }^{1}$, S. Prakash ${ }^{2}$, J. Rodrigues ${ }^{3} \&$ J. Farrant ${ }^{3}$ \\ ${ }^{1}$ Department of Food Science and Nutrition, University of Zambia, Lusaka, Zambia \\ ${ }^{2}$ Department of Chemistry, University of Zambia, Lusaka, Zambia \\ ${ }^{3}$ Department of Molecular and Cell Biology, University of Cape Town, 7701 Rondebosch, South Africa \\ Correspondence: V. Nyau, Department of Food Science and Nutrition, University of Zambia, Lusaka, Zambia. \\ E-mail: vincentnyau@yahoo.co.uk
}

Received: October 21, 2016

doi:10.5539/jfr.v6n2p24

\author{
Accepted: November 25, $2016 \quad$ Online Published: February 7, 2017 \\ URL: http://dx.doi.org/10.5539/jfr.v6n2p24
}

\begin{abstract}
Processing of legumes before consumption has several effects on micronutrients, macronutrients and phytonutrients. This study was undertaken to investigate the effect of domestic processing on antioxidant activities and phenolic phytochemicals of the red bambara groundnuts and red beans. The study employed in vitro antioxidant assays (DPPH and FRAP) to screen for antioxidant properties, HPLC-PDA-ESI-MS and Folin Ciocalteu assay to screen for phenolic phytochemical profiles. Domestic cooking displayed positive effects on the antioxidant activity and phenolic phytochemical profiles of the two legumes. The free radical scavenging speed increased 10-fold in the methanolic extract from cooked red bambara groundnuts compared to uncooked. By contrast, the free radical scavenging speed increased 20-fold in the methanolic extract from cooked red beans compared to uncooked. HPLC-PDA-ESI-MS profiles of the cooked red bambara groundnuts and red beans revealed a number of emergent phenolic compounds, mainly flavonoids. These data indicate that cooking appear to enhance the nutraceutical profiles of the legumes investigated.
\end{abstract}

Keywords: domestic cooking, polyphenols, antioxidant, bambara groundnuts, common beans

\section{Introduction}

Generally most food legumes have to be processed before consumption. Different processing methods are applied depending on the intended use of the final product and the availability of the processing facilities. The most common method of processing is domestic cooking and involves boiling the seed legumes until soft using fire wood or electricity as heating sources.

Concentration of plant secondary metabolites having antioxidant activity is affected by a number of factors, including genetics and growing conditions (Kalt, 2005). Processing is another important factor that can impact total antioxidant activity (Papas, 1996). Knowledge about the fate of total antioxidant activity as a result of home processing may have a significant impact on consumers' food selection and processing (Danesi, 2009). Few studies have been done on seed legumes to investigate the effect of domestic processing on the total antioxidant activity and the phytochemical profiles. Although common beans are widely consumed all over the world, very little information is available in the literature regarding the changes in total phenols, total flavonoids and antioxidant activities following food preparation methods (Akillioglu and Karakaya, 2010).

In this study, the effect of domestic cooking on the antioxidant activities and phenolic phytochemical profiles of the red Zambian market classes of common beans and bambara groundnuts was investigated. Previous studies have shown that red beans possess excellent antioxidant activities in the raw form (Nyau et al., 2016) and therefore need to be evaluated further to determine hydrothermal effects on these activities. On the other hand, HPLC-PDA-ESI-MS profiling of the red bambara groundnuts revealed more phenolic compounds than the brown bambara groundnuts investigated (Nyau et al., 2015). This prompted further investigations in the current study to assess the changes in the polyphenolic phytochemical profiles that occur due to hydrothermal cooking. The methanolic extract was used because most likely it contained both hydrophilic and hydrophobic compounds. Antioxidant properties of cooked seeds were measured based on their free radical scavenging activity and ferric reducing power. The free radical scavenging ability of the methanolic extracts is reported on the basis of kinetic 
behaviour of the DPPH free radicals with antioxidants in the two legumes. The ferric reducing power is reported on the basis of the number of mmoles $\mathrm{Fe}^{2+}$ produced in the reduction of $\mathrm{Fe}^{3+}$ by the antioxidants in the extracts.

\section{Materials and Methods}

\subsection{Sample Collection}

The red common beans (Phaseolus vulgaris L) and red bambara groundnuts (Vigna subterranea L. Verdc) were obtained directly from the farmers immediately after harvest. The two legumes are shown in Figure 1. In order to make the samples representative, an attempt was made to collect each seed type from 15 farmers in the growing areas with not less than $0.5 \mathrm{~kg}$ per farmer and a total of 15 samples per seed was collected.

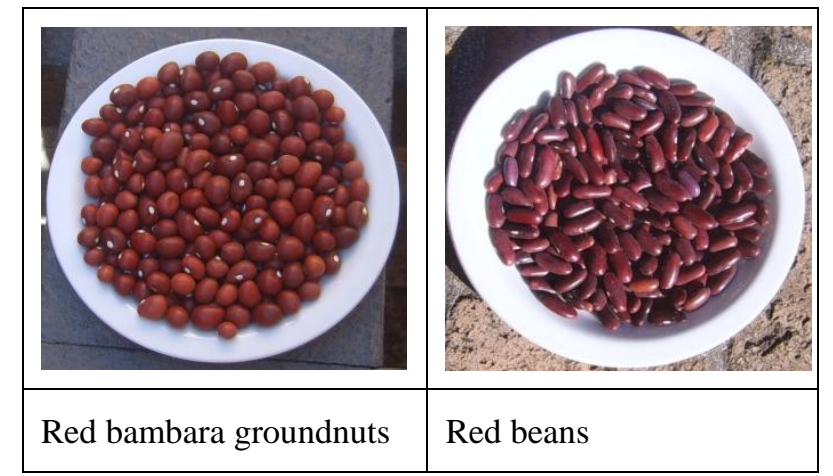

Figure 1. Red bambara groundnuts and red beans investigated

\subsection{Cooking Treatment}

Approximately $400 \mathrm{~g}$ of the seeds in $1.5 \mathrm{~L}$ water of each legume were cooked using the traditional cooking method commonly used in Zambia. Seeds were boiled in tap water on a hot plate at the temperature of $100 \pm 5$ ${ }^{\circ} \mathrm{C}$, until they felt soft using the finger compression test. The finger compression test is a sensory based approach in which texture is treated as a perception or how a food material feels with the fingers. It is a very rapid and useful method employed to determine firmness or the degree of softness by consumers (Mitcham et al., 1996). In this experiment, the beans were considered soft if they were able to deform under moderate pressure when compressed between the index finger and the thumb. It took 410 and 430 minutes for the red beans and Bambara groundnuts to cook respectively.

\subsection{Preparation of Extracts of Cooked Beans and Bambara Groundnuts}

The cooked seeds together with the water that remained after cooking were immediately frozen at $-80{ }^{\circ} \mathrm{C}$ and freeze dried to obtain the dried material that was later ground to a powder. Approximately $15 \mathrm{~g}$ of seed powder in $150 \mathrm{ml}$ of $70 \%$ methanol was sonicated for 30 minutes at $25^{\circ} \mathrm{C}$ using the Eumax UD500SH $40 \mathrm{kHz}$ ultrasonic bath. After extraction, the mixture was centrifuged at a speed of $10,000 \mathrm{rpm}$ for 15 minute using Beckman Coulter JE centrifuge. The resulting supernatant was first concentrated to $30 \mathrm{ml}$ by evaporation under reduced pressure in a rotary evaporator (Buchi R-210 model, Switzerland) to remove methanol. The extract was then frozen at $-80{ }^{\circ} \mathrm{C}$ and freeze dried to obtain a powdered methanolic extract using the Telstar LyoQuest -85 freeze dryer. The freeze dried extracts were stored at $-4^{\circ} \mathrm{C}$ until further analysis

\subsection{Preparation of Extracts from the Raw Beans and Bambara Groundnuts}

Approximately $15 \mathrm{~g}$ of seed powder in $150 \mathrm{ml}$ of $70 \%$ methanol was sonicated for 30 minutes at $25^{\circ} \mathrm{C}$ using the Eumax UD500SH $40 \mathrm{kHz}$ ultrasonic bath. After extraction, the mixture was centrifuged at a speed of 10,000 rpm for 15 minute in Beckman Coulter JE centrifuge. The supernatant was first concentrated to $30 \mathrm{ml}$ by evaporation under reduced pressure in a rotary evaporator (Buchi R-210 model, Switzerland) to remove methanol. The extract was then frozen at $-80{ }^{\circ} \mathrm{C}$ and freeze dried to obtain a powdered methanolic extract using the Telstar LyoQuest -85 freeze dryer. The freeze dried aqueous and methanolic extracts were stored at $-4{ }^{\circ} \mathrm{C}$ until further analysis.

\subsection{Determination of Total Polyphenols}

Total polyphenols were determined by the Folin Ciocalteu assay according to the method of Makkar et al., (2000). To $100 \mu 1$ of sample extract, $400 \mu \mathrm{l}$ of distilled water was added followed by the addition of $250 \mu 1$ Folin Ciocalteu reagent. $20 \%$ Sodium carbonate $(1.25 \mathrm{ml})$ was then added and the mixture was incubated for 40 min. Absorbancies were read at $725 \mathrm{~nm}$ after 40 minutes using a spectrophotometer (Ultrospec 1000 model, England) 
against the blank (70\% methanol or water) depending on whether it was the water or $70 \%$ methanol extract. The amount of total polyphenols was calculated as gallic acid equilvalents from the calibration curve of gallic acid standard solution and expressed as mg gallic acid equivalents/ $100 \mathrm{~g}$ DW. The experiment was conducted three times and all measurements were performed in triplicate.

\subsection{HPLC-DAD-ESI-MS Instrumentation and Chromatographic Conditions}

The freeze dried $70 \%$ methanolic extract powder of common beans were analysed using a Waters ZMD 4000 system that was equipped with a Waters 2690 HPLC, Waters 996 photodiode array, ZMD mass spectrophotometer, 717 Plus autosampler, and a quaternary pump (Waters Corp, Milford, MA, USA). Separations were carried out on a $300 \times 3.9 \mathrm{~mm}, 4 \mu \mathrm{m}$ reversed phase Nova-Pak C18 (Waters) column that was maintained at $40^{\circ} \mathrm{C}$. The photodiode array detector (PDA) was linked directly to a sprayer needle where ions were generated by electrospray ionisation (ESI) in a negative mode. The mobile phase A consisted of 5\% (v/v) acetonitrile/water, containing $0.1 \%(\mathrm{v} / \mathrm{v})$ formic acid and mobile phase B consisted of $100 \%$ acetonitrile containing $0.1 \%(\mathrm{v} / \mathrm{v})$ formic acid. The sample was injected at a volume of $25 \mu 1$. The elution profile consisted of a stepwise linear gradient from $0 \%$ to $28 \%$ solvent B for 22 minutes with a flow rate of $0.3 \mathrm{ml} / \mathrm{min}$. The PDA detector was set to a scanning range of 200 to $700 \mathrm{~nm}$ and the UV-Vis absorption spectra were recorded online during the HPLC analysis. Phenolic acids and flavonols were detected at 280 and $360 \mathrm{~nm}$, respectively. Continuous mass spectra data were recorded on a full scan negative ionisation mode for a mass range of $\mathrm{m} / \mathrm{z} 85$ to 1000 . The capillary voltage was set at $2.5 \mathrm{kV}$, the cone at $20 \mathrm{~V}$ and the extractor at $5 \mathrm{~V}$. Nitrogen gas was used for nebulising and drying at different fragmentation voltages. Data acquisition was controlled using MassLynx 4.1 (Micromass, Waters Corp., Beverly, MA, USA). The gradient solvent system used for the analysis of phenolic compounds is summarised in Table 1.

Table 1. Gradient solvent system for analysis of phenolic compounds by HPLC -PDA-ESI-MS

\begin{tabular}{ccc}
\hline & \multicolumn{2}{c}{ Composition of the mobile phase (\%) } \\
\cline { 2 - 3 } Time (minutes) & *Mobile phase & *Mobile phase \\
\hline 1 & $(\mathbf{A})$ & $($ B) \\
22 & 100 & 0 \\
22.50 & 72 & 28 \\
23 & 60 & 40 \\
24.50 & 0 & 100 \\
25 & 0 & 100 \\
26 & 100 & 0 \\
\hline
\end{tabular}

*Mobile phase A consisted of $\overline{5 \%(\mathrm{v} / \mathrm{v}) \text { acetonitrile/water, containing } 0.1 \%(\mathrm{v} / \mathrm{v}) \text { formic; mobile phase } B}$ consisted of $100 \%$ acetonitrile containing $0.1 \%(v / v)$ formic acid.

\subsection{Preparation of the Samples for HPLC-DAD-ESI-MS Analysis}

Preparation of the test solution for HPLC-DAD-ESI-MS was done according to the procedure by Gülçin et al., (2010) with slight modifications. One hundred $\mathrm{mg}$ of the freeze dried $70 \%$ methanolic extract was dissolved in 5 $\mathrm{ml}$ of ethanol-water $(50: 50 \mathrm{v} / \mathrm{v})$. One hundred $\mu \mathrm{l}$ of the prepared extract was transferred into a $5 \mathrm{ml}$ volumetric flask and diluted to the volume with ethanol-water (50:50). From the final solution, an aliquot of $1.5 \mathrm{ml}$ was transferred into a capped autosampler vial and $25 \mu 1$ of the sample was injected into the HPLC-DAD-ESI-MS system. Identification of phenolic compounds was accomplished using UV spectra and ESI-MS spectral data and by comparison with published data reported in the literature. Authentic standards were also used where available by comparing their chromatograms with those of the samples. The available standards were $t$-ferrulic acid, gallic acid, salicylic acid, $p$-coumaric acid, epicatechin and catechin.

\subsection{HPLC-PDA-ESI-MS Quantification of Phenolic Compounds}

Quantification of individual phenolic compounds could only be done where authentic standards were available. The available standards were $t$-ferrulic acid, gallic acid, salicylic acid, $p$-coumaric acid, epicatechin and catechin. The concentrations of ferrulic acid, gallic acid, salicylic acid, $p$-coumaric acid, epicatechin and catechin were obtained from the linear regression equations of the standard curves (Gülçin et al., 2010). The experiment was conducted three times and all measurements were done in duplicate. 


\subsection{Determination of Free Radical Scavenging Activity of the Bambara Groundnuts}

DPPH stable free radicals are reduced to DPPH-H leading to discoloration from purple to yellow and consequently a decrease in absorbance. The degree of discoloration indicates the scavenging potential of the antioxidant compounds (Pal et al., 2008). This assay therefore involves the measurement of hydrogen atom transfer or electron donation from a potential antioxidant to free radical molecules (Becker et al., 2004). First, it was important to study the kinetic behaviour of the extracts towards DPPH free radicals when the freeze dried extracts from each legume were added at the same concentration. The knowledge of the kinetics of atom transfer is important because free radicals in the organism are short-lived species, implying that the impact of a substance as an antioxidant depends on its fast reactivity towards free radicals (Villaño et al., 2007). The free radical scavenging kinetic determinations were adapted from (Villaño et al., 2007). Under the experimental conditions used, the DPPH concentration was in large excess with respect to that of the extracts in order to follow pseudo first-order kinetics. This was done to exhaust the hydrogen donating capacity of the extracts. The excess concentration of DPPH $(200 \mathrm{mM})$ was determined to be the optimum concentration after performing a number of runs with the extracts. This was the only way the excess DPPH concentration could be determined since it was not possible to work it out based on the DPPH: antioxidant molar ratios as the antioxidants in the extracts were not pure compounds. In the assessement of the kinetic behaviour, $2 \mathrm{ml}$ of the extracts were added at the same concentration $(400 \mu \mathrm{g} / \mathrm{ml})$ to $2 \mathrm{ml}$ of DPPH radical solution $(200 \mathrm{mM})$ prepared in $95 \%$ methanol. The reaction was run at room temperature within a time period of 80 minutes. The absorbances of the mixture were automatically measured every 10 seconds using the spectrophotometer at $517 \mathrm{~nm}$ connected to a computer and the output was displayed using SWIFT 1000 software (Ultraspec 1000 model, England). From the reaction between an antioxidant and DPPH;

$(\mathrm{DPPH})+(\mathrm{Y}-\mathrm{H}) \rightarrow \mathrm{DPPH}-\mathrm{H}+(\mathrm{Y})$, it can be deduced that:

$$
-\frac{d[D P P H]}{d t}=k[D P P H][Y-H]
$$

Considering that DPPH was in excess and therefore the experiment was under pseudo first-order conditions, one can say:

$$
\operatorname{In} A=\operatorname{In} A_{o}-k t
$$

Where $A_{0}$ is the absorbance of the reaction mixture (DPPH and the extract) at $t=0 ; A$ is the absorbance of the reaction mixture (DPPH and extract) at time $t$.

The pseudo first order rate constant ' $k$ ' for the reaction of the antioxidants in the extracts and DPPH in the first seconds of the reaction was calculated from the slopes of $\operatorname{In} A$ versus time plots.

The percentage of DPPH remaining at any time $t$ can be determined as:

$$
\% D P P H_{\text {remaining }}=\frac{A_{t}}{A_{0}} X 100
$$

(Villaño et al., 2007)

Where $A_{0}$ is the initial absorbance and $A_{t}$ is the absorbance at time $=t$, both measured at $517 \mathrm{~nm}$ respectively. Plots of percentage DPPH versus time were constructed to show the disappearance pattern of the DPPH with time in the presence of each extract.

\subsection{Determination of Ferric Reducing Antioxidant Power (FRAP)}

The FRAP assay was used to determine the ferric reducing antioxidant power of the two legumes (Benzie, 1996). The method measures the ferric reducing ability of the antioxidants compounds in the extracts. At low $\mathrm{pH}$, ferric-2,4,6-tri-2-pyridyl-s-triazine (TPTZ) complex $\left(\mathrm{Fe}^{3+} \mathrm{TPTZ}\right)$ is reduced to the ferrous form $\mathrm{Fe}^{2+}$ in the presence of the antioxidant producing an intense blue colour with an absorption maximum at $593 \mathrm{~nm}$. Powdered sample of bambara groundnuts or beans $(5 \mathrm{~g})$ in $50 \mathrm{ml}$ of $70 \%$ methanol or water was sonicated for 30 minutes at $25{ }^{\circ} \mathrm{C}$ followed by centrifugation at $10,000 \mathrm{rpm}$ for 15 minutes at $4{ }^{\circ} \mathrm{C}$ to obtain a clear supernatant. Working FRAP reagent was prepared by mixing $25 \mathrm{ml}$ of acetate buffer $(300 \mathrm{mM}, \mathrm{pH} 3.6) ; 2.5 \mathrm{ml}$ ferric chloride solution (prepared by dissolving $54 \mathrm{mg}$ ferric chloride in $10 \mathrm{ml}$ distilled water) and $2.5 \mathrm{ml}$ TPTZ solution (prepared by 
dissolving $31 \mathrm{mg}$ TPTZ in $40 \mathrm{mM} \mathrm{HCl}$ at $50{ }^{\circ} \mathrm{C}$ ). The mixture was placed in a water bath at $37{ }^{\circ} \mathrm{C}$ for 10 minutes. The assay was performed as follows: $1 \mathrm{ml}$ of water and $80 \mu 1$ of the test sample were pipetted into a cuvette. About $600 \mu 1$ of the incubated FRAP reagent was added to the cuvette and mixed by inversion. A reagent blank was prepared as above with $80 \mu \mathrm{l}$ water added instead of the test sample. The change in absorbance was recorded at $593 \mathrm{~nm}$ using a spectrophotometer after exactly 4 minutes (Ultrospec 1000 model, England). The amount of $\mathrm{Fe}^{2+}$ produced from the reduction of $\mathrm{Fe}^{3+}$ by the extract was calculated from the standard curve prepared from ferrous sulphate solution and results were expressed as $\mathrm{mg} \mathrm{Fe}^{2+} / 100 \mathrm{~g}$ dry sample. The experiment was conducted three times and all measurements were performed in triplicate.

\subsection{Statistical Analysis}

Statistical analysis was performed using S-PLUS 6 Windows Professional 2001. Experimental results were expressed as mean values \pm standard error. Data was analysed using two-sample t-test. Values at $p<0.05$ were considered statistically significant.

\section{Results}

\subsection{Free Radical Scavenging Activity of Cooked Red Bambara Groundnuts and Red Beans}

Figure 2 presents the disapearance of the DPPH free radicals in the presence of methanolic extract of cooked and uncooked red bambara groundnuts. The initial decay of DPPH was faster in the presence of methanolic extracts from the cooked red bambara groundnuts than in the uncooked. The pseudo first-order rate constant was 0.43 $\mathrm{min}^{-1}$ in the cooked and $0.042 \mathrm{~min}^{-1}$ in the uncooked bambara groundnuts (Table 2). This is a very desirable property for the antioxidants because free radicals are very fast reactive species that equally need fast- acting scavengers. There was a significant difference in the amount of DPPH free radicals scavenged at the end of the incubation time by the extracts from the uncooked and cooked red bambara groundnuts. It was intriguing to note that the amount of the DPPH free radicals scavenged by the extracts from the cooked red bambara groundnuts was similar to that scavenged by the positive reference standard trolox towards the end of the assay period chosen (Table 2). This observation implies that the cooked nuts most likely, contained more antioxidant compounds than the uncooked nuts.

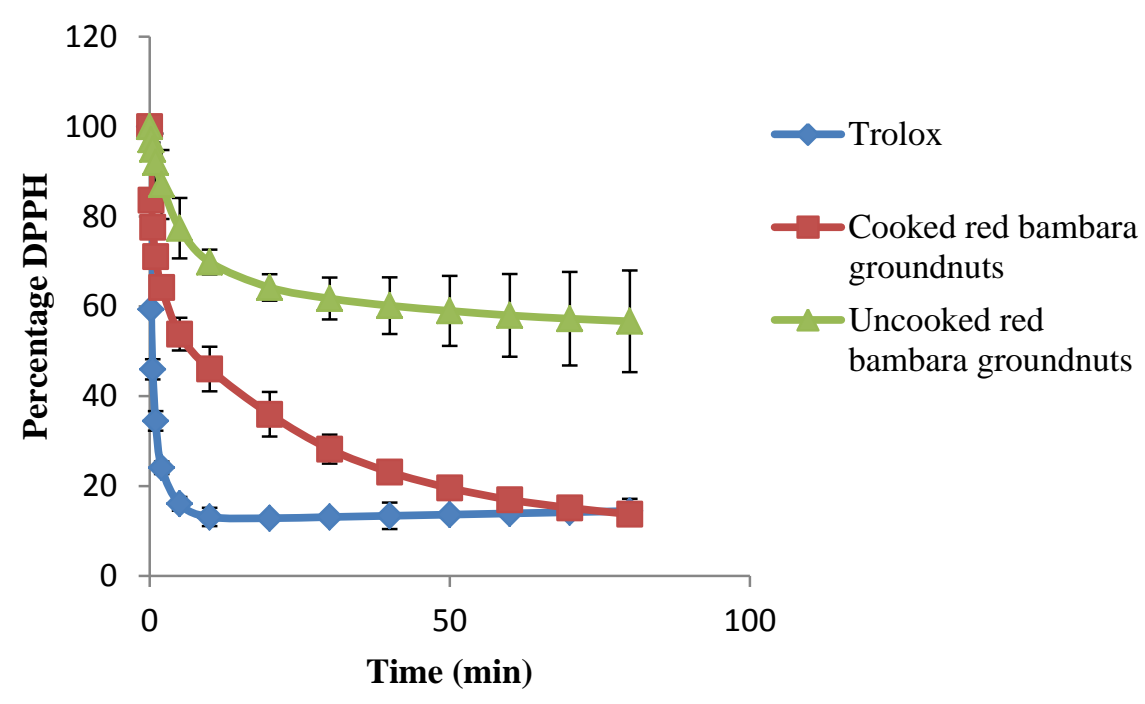

Figure 2. Disappearance pattern of DPPH free radicals with time in the presence of $70 \%$ methanol extracts of cooked and uncooked red bambara groundnuts 
Table 2. Pseudo-first order rate constant of antiradical (Y-H) in cooked red bambara groundnuts and red beans and the amount of DPPH scavenged after 80 minutes of incubation

\begin{tabular}{llcc}
\hline \multicolumn{2}{c}{$\begin{array}{c}\text { Market classes of bambara groundnuts } \\
\text { and common beans }\end{array}$} & $\begin{array}{c}\text { Pseudo-first order rate } \\
\text { constant }(\mathbf{K})\left[\mathbf{m i n}^{-1}\right]\end{array}$ & $\begin{array}{c}\text { Amount DPPH quenched [\%] } \\
\text { after 80 minutes incubation }\end{array}$ \\
\hline $\begin{array}{l}\text { Red } \\
\text { groundnuts }\end{array}$ & bambara & $0.042^{\mathrm{a}}$ & $44.01 \pm 2.96^{\mathrm{a}}$ \\
& $\begin{array}{l}\text { Control } \\
\text { (uncooked) }\end{array}$ & $0.430^{\mathrm{b}}$ & $86.38 \pm 1.36^{\mathrm{b}}$ \\
Red beans & $\begin{array}{l}\text { Cooked } \\
\end{array}$ & $0.050^{\mathrm{a}}$ & $62.01 \pm 2.21^{\mathrm{a}}$ \\
& $\begin{array}{l}\text { Control } \\
\text { (uncooked) } \\
\text { Cooked }\end{array}$ & $1.120^{\mathrm{b}}$ & $65.22 \pm 2.36^{\mathrm{b}}$ \\
\hline
\end{tabular}

Trolox $K=1.55$, amount quenched in 80 minutes $=85.5 \%$. Means in the same column for each legume type with different superscripts were significantly $(p<0.05)$ different

The free radical scavenging pattern by antioxidants in the cooked and uncooked red beans is presented in Figure 3. The disappearance pattern of the DPPH in the presence of the extract from the cooked red beans was much faster than that of the uncooked. There was a very sharp initial decay with a pseudo first-order rate constant (K) of $1.12\left(\mathrm{~min}^{-1}\right)$ for the cooked red beans compared to $0.05\left(\mathrm{~min}^{-1}\right)$ for the uncooked beans (see Table 2 above). The cooked extract had a better pseudo first-order rate kinetic than the extract from the uncooked beans. As discussed above with respect to red bambara groundnuts, this is a very desirable attribute for the antioxidants because free radicals react extremely quickly and require fast-acting antioxidants.

The results from our study are in agreement with Akillioglu and Karakaya (2009) who reported the increase in the amount of DPPH free radicals scavenged when common beans were cooked by first soaking in water for 3 hours prior to cooking. However, the study by Akillioglu and Karakaya did not report the free radical scavenging pattern by elaborating on the kinetics of the DPPH free radicals and the antioxidants in common beans in the course of the reaction.

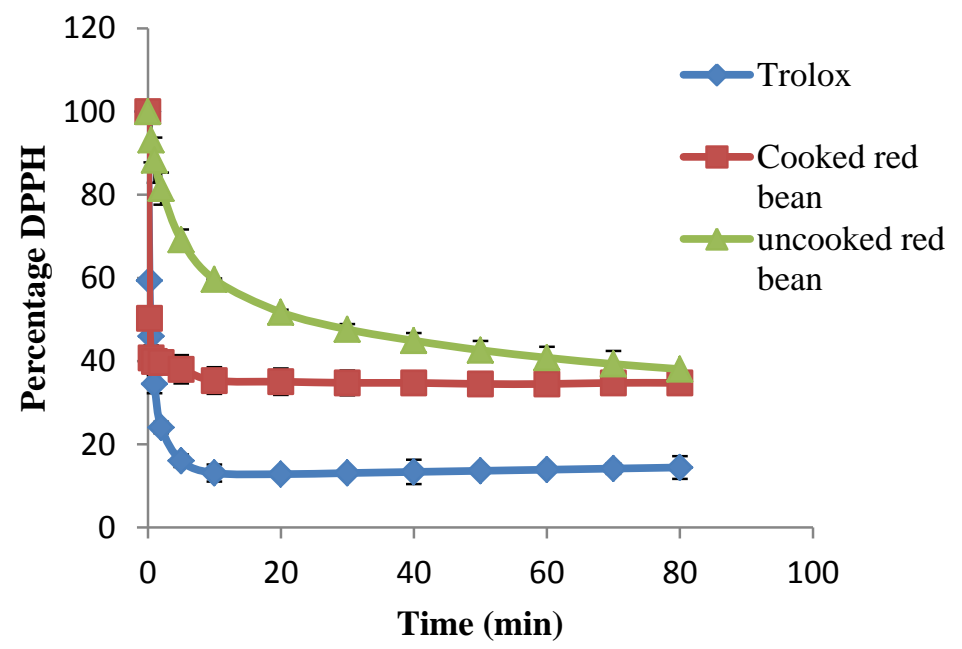

Figure 3. Disappearance pattern of DPPH free radicals with time in the presence of $70 \%$ methanolic extracts of cooked and uncooked red beans

\subsection{Ferric Reducing Antioxidant Power of the Cooked Red Bambara Groundnuts and Red Beans}

The FRAP values of the cooked red bambara groundnuts and red beans are presented in Table 3. The FRAP values of the uncooked and cooked red bambara groundnuts were not significantly different. However, the extract from the cooked red beans had greater reducing power than the extract from the uncooked material, suggesting that the cooked sample contained more antioxidant compounds or more reactive antioxidants than the uncooked. 
Table 3. FRAP values for the cooked red bambara groundnuts and red beans

\begin{tabular}{llc}
\hline Market classes of bambara groundnuts and common beans & FRAP values (mmole $\left.\mathbf{F e}^{\mathbf{2 +}} / \mathbf{1 0 0} \mathbf{g ~ D W}\right)$ \\
\hline Red Bambara groundnuts & Control (uncooked) & $8.01 \pm 0.41^{\mathrm{a}}$ \\
& Cooked & $8.55 \pm 0.02^{\mathrm{a}}$ \\
Red beans & Control (uncooked & $4.81 \pm 0.01^{\mathrm{b}}$ \\
& Cooked & $5.05 \pm 0.04^{\mathrm{b}}$ \\
\hline
\end{tabular}

Means in the same column for each legume type with different superscripts were significantly $(p<0.05)$ different.

\subsection{Total Polyphenol Levels in Cooked Red Bambara Groundnuts and Red Beans}

Total polyphenol levels in cooked red bambara groundnuts and red beans are presented in Table 4. There was an increase in total polyphenol content in both the red bambara groundnuts and red beans after cooking. Total polyphenol content increased by $6 \%$ in red bambara groundnuts and $41 \%$ in red beans respectively.

Table 4. Total polyphenol concentration of cooked red bambara groundnuts and red beans

\begin{tabular}{llc}
\hline Market classes of bambara groundnuts and common beans & Total polyphenols (mg GAE / 100 g DW) \\
\hline \multirow{2}{*}{ Red Bambara groundnuts } & Control (uncooked) & $109.12 \pm 2.35^{\mathrm{a}}$ \\
Red beans & Cooked & $116.03 \pm 3.27^{\mathrm{b}}$ \\
& Control (uncooked) & $84.50 \pm 2.55^{\mathrm{a}}$ \\
& Cooked & $119.31 \pm 3.04^{\mathrm{b}}$ \\
\hline
\end{tabular}

Means in the same column for each legume type with different superscripts were significantly $(p<0.05)$ different.

\subsection{Levels of Individual Phenolic Compounds in Cooked Red Bambara Groundnuts and Red Beans}

Quantitative contents of $t$-ferrulic acid, $p$-coumaric acid, catechin, epicatechin and salicylic acid of cooked red bambara groundnuts and red beans are presented in Figures 4 and 5. Generally, there was an increase in all phenolic compounds investigated in red bambara groundnuts, except for salicylic acid which showed a 59\% decrease after cooking. Epicatechin increased by $92 \%$, followed by catechin $(54 \%), t$-ferrulic acid (39\%) and $p$-coumaric acid (30\%) respectively. Similarly, there was an increase in the concentration of all the phenolic compounds investigated in red beans after cooking, except for salicylic acid which was completely missing. Phenolics in the flavonol category recorded higher increase than phenolic acids. Epicatechin increased by $96 \%$, followed by catechin (80\%), $p$-coumaric (41\%) and $t$-ferrulic acid (40\%) respectively.

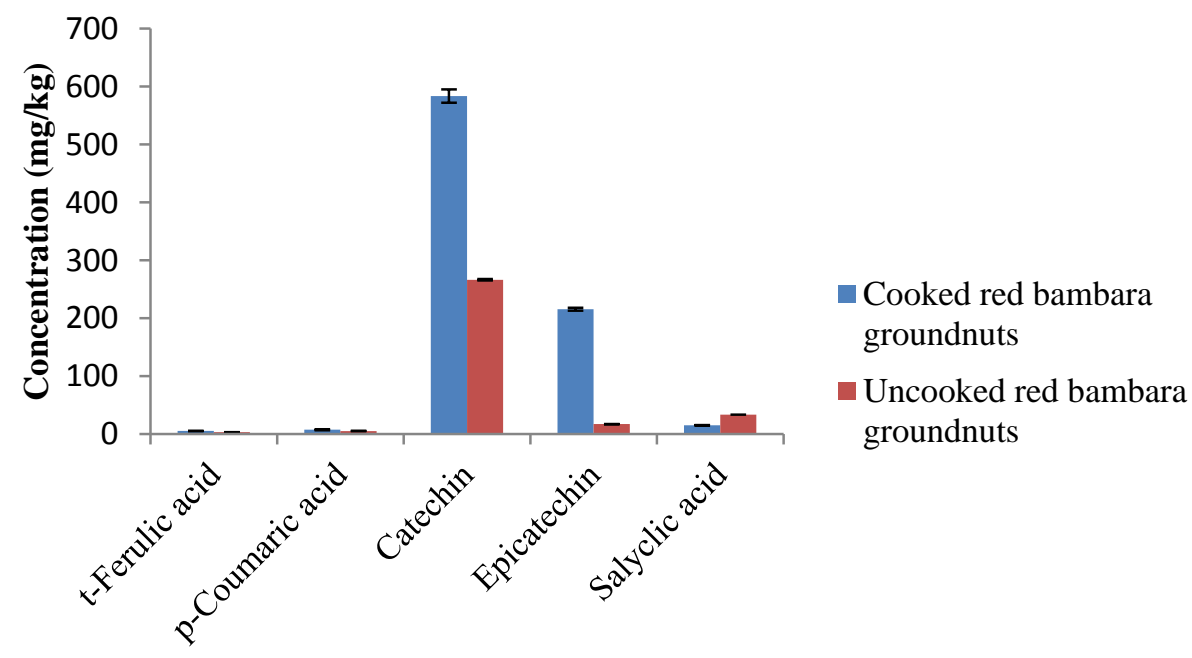

Phenolic compounds

Figure 4. Concentration of individual phenolic compounds of $70 \%$ methanol extracts of cooked and uncooked red bambara groundnuts 


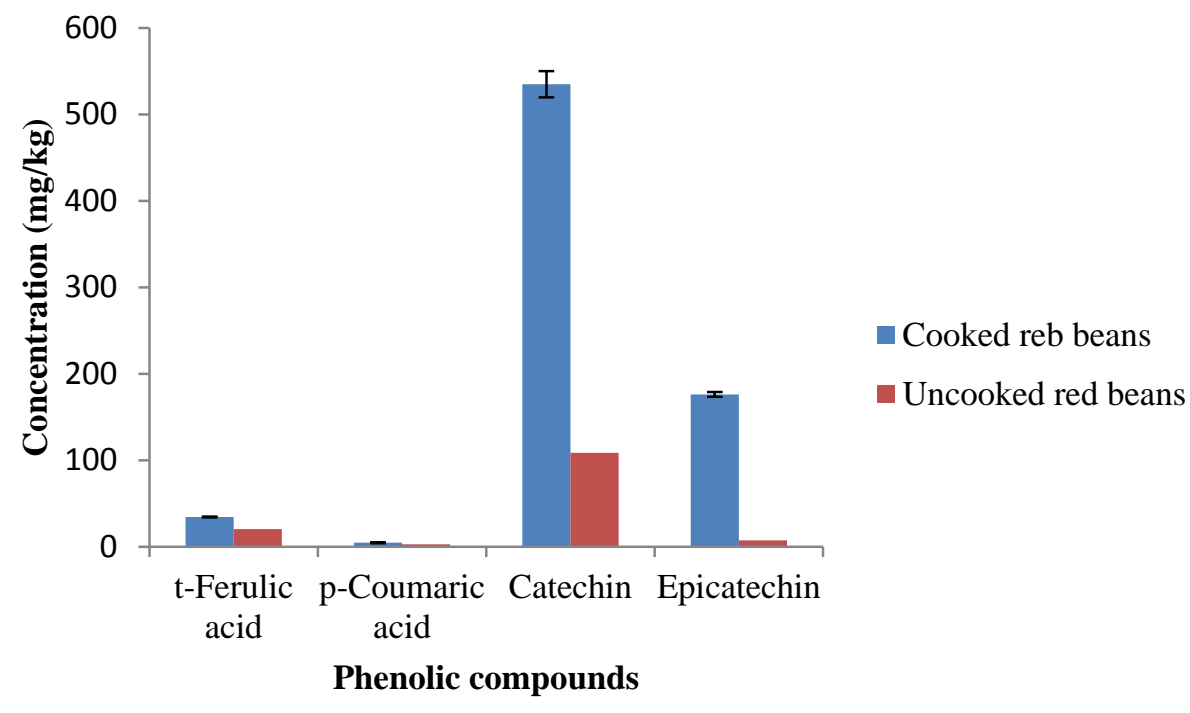

Figure 5. Concentration of individual phenolic compounds of $70 \%$ methanol extracts of cooked and uncooked red beans

\subsection{HPLC-PDA-ESI-MS Profiles of the Cooked Red Bambara Groundnuts and Red Beans}

The HPLC-PDA-ESI-MS chromatograms of methanolic extracts from the uncooked and cooked red bambara groundnuts and red beans are compared in Figures $6 \& 7$ (for red bambara groundnuts) and 8 \& 9 (for red beans) respectively. A slight drift in the retention times of peaks was observed in these runs. This may be attributed to minor temperature changes or the increase in the back pressure in the column. Shifts in laboratory temperature and a slight increase of the back pressure in the column may cause drifting retention times in long automated operations (Waters Corporation, 2002).

Significant differences were observed in the HPLC-PDA-ESI-MS profiles of uncooked and cooked seeds for both legumes. In the profile of cooked red bambara groundnuts (Figure 6), there were ten emergent deprotonated molecules $\left[\mathrm{M}-\mathrm{H}^{-}\right]$of $\mathrm{m} / \mathrm{z} 341,639,305,495,577,451,323,389,625$ and 463 respectively. In the profile of the cooked red beans (Figure 8), there were five new deprotonated molecules $\left[\mathrm{M}-\mathrm{H}^{-}\right]$of m/z 164, 451, 608, 463 and 447 that emerged respectively. Differences in the number of emergent compounds between bambara groundnuts and common beans confirm that there are variations in the amount, types and distribution of phytochemicals in legumes.

For both red bambara groundnuts and red beans, there were variations in the peak heights (concentrations) for the compounds that were detected in the uncooked and cooked seeds. Peak heights were higher in the extracts of the cooked than the uncooked seeds, confirming that more phytochemicals are extracted when the seeds are cooked. These results suggested that there are changes in the phytochemical profiles of bambara groundnuts and common beans after the cooking process and validates our earlier observation on the changes in total polyphenol contents and concentrations of individual phenolic compounds. The observed changes are positive and dispel the generally held concerns that nutrients and phytonutrients are significantly lost during the cooking process. 


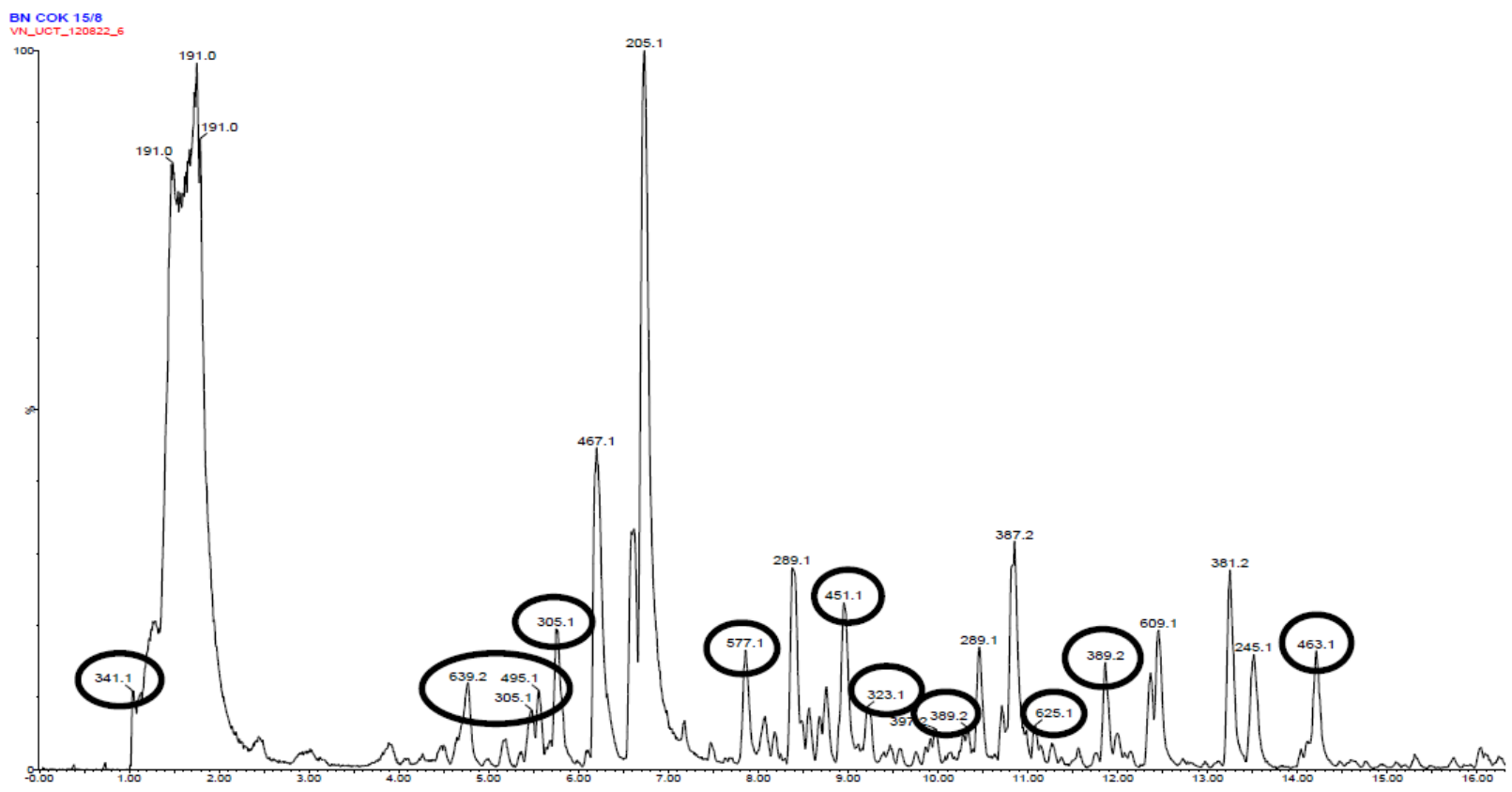

Figure 6. HPLC-PDA-ESI-MS chromatogram of $70 \%$ methanol extract of cooked red bambara groundnuts. represents emergent compounds after processing. Number on top of each peak is the $\mathrm{m} / \mathrm{z}$ of the deprotonated molecule $\mathrm{M}-\mathrm{H}]^{-}$of each compound

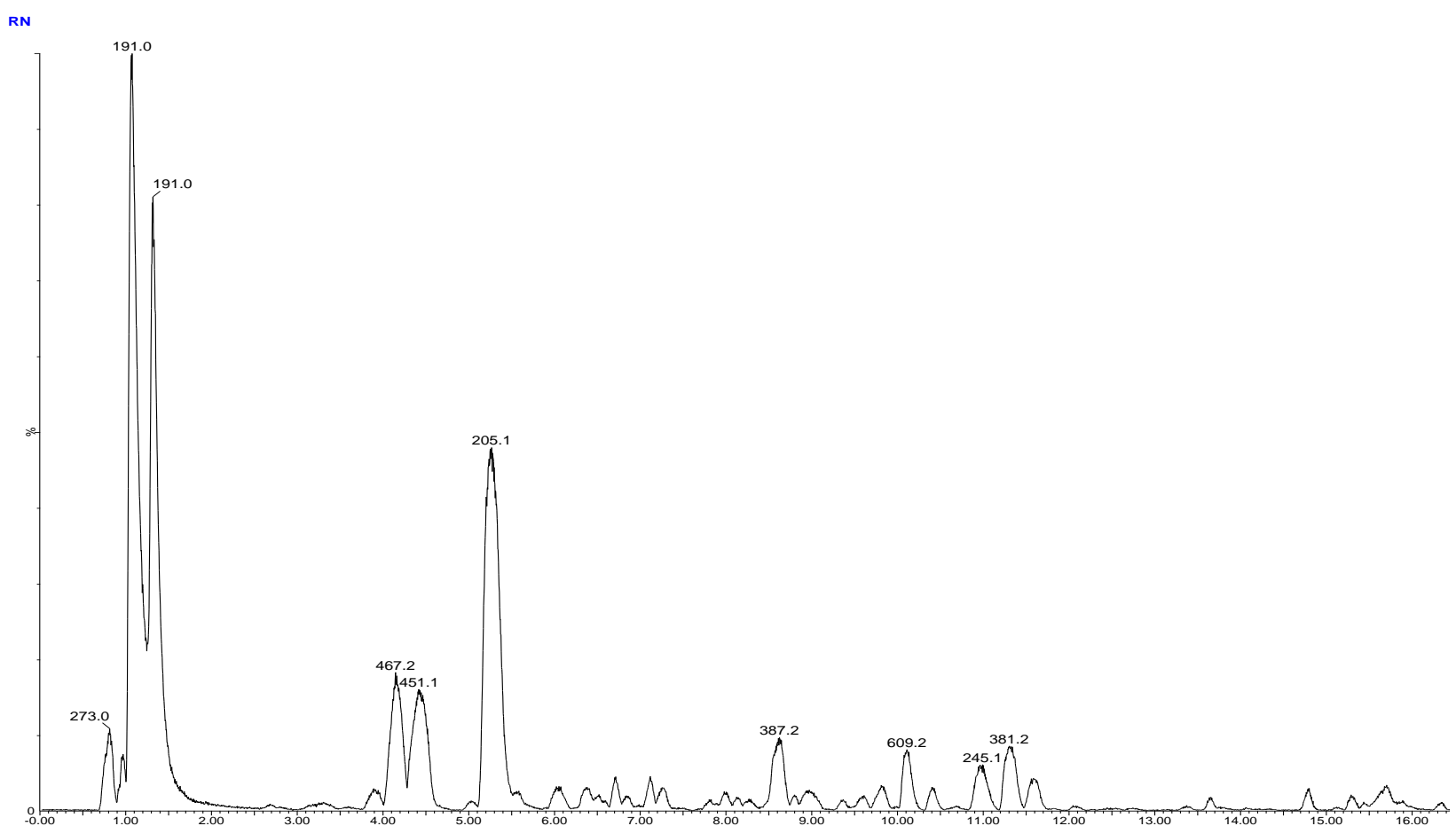

Figure 7. HPLC-PDA-ESI-MS chromatogram of $70 \%$ methanol extract of the uncooked red bambara groundnuts. Number on top of each peak is the $\mathrm{m} / \mathrm{z}$ of the deprotonated molecule $[\mathrm{M}-\mathrm{H}]-$ of each compound 


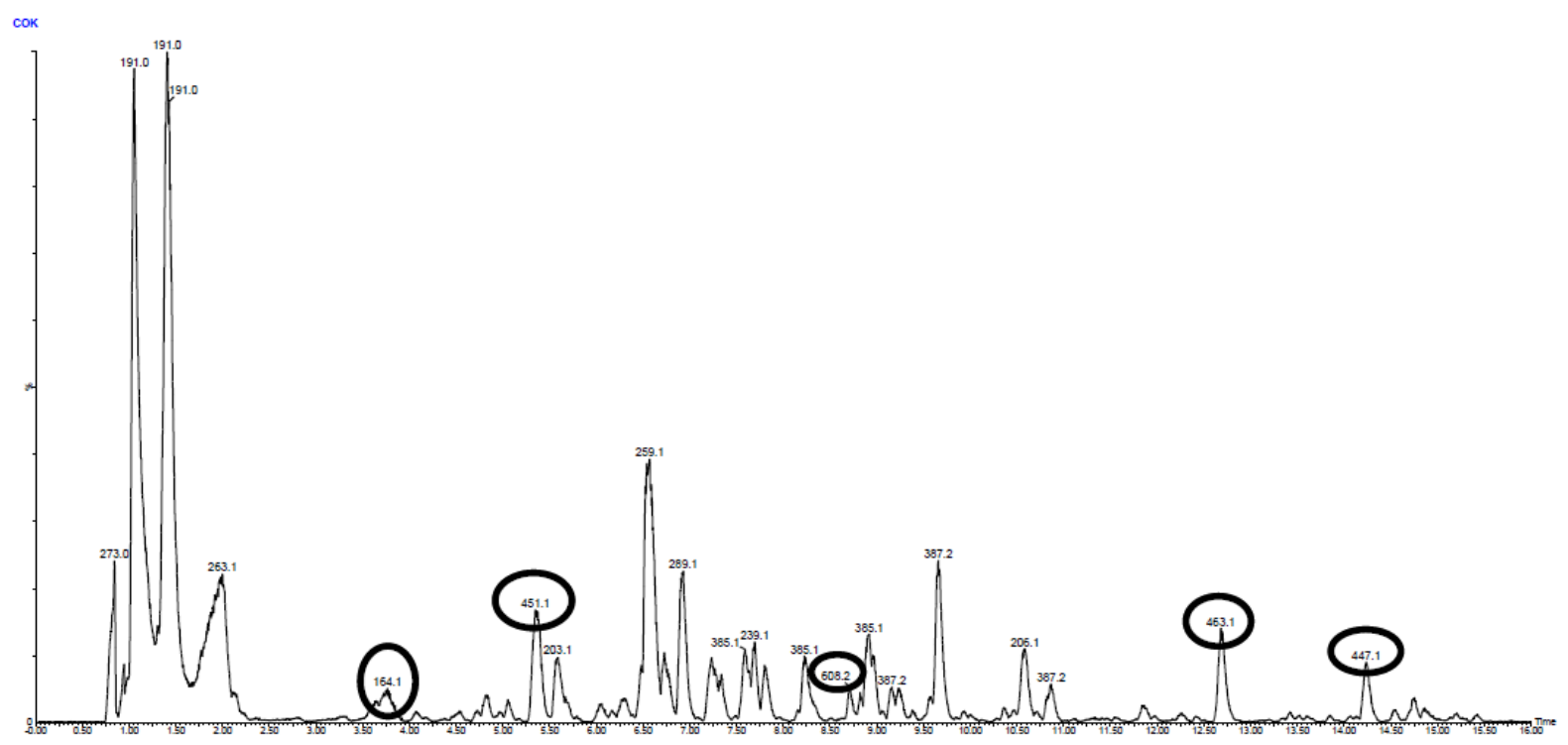

Figure 8. HPLC-PDA-ESI-MS chromatogram of 70\% methanol extract of cooked red beans. represents emergent compounds after processing. Number on top of each peak is the $\mathrm{m} / \mathrm{z}$ of the deprotonated molecule $[\mathrm{M}-\mathrm{H}]^{-}$of each compound

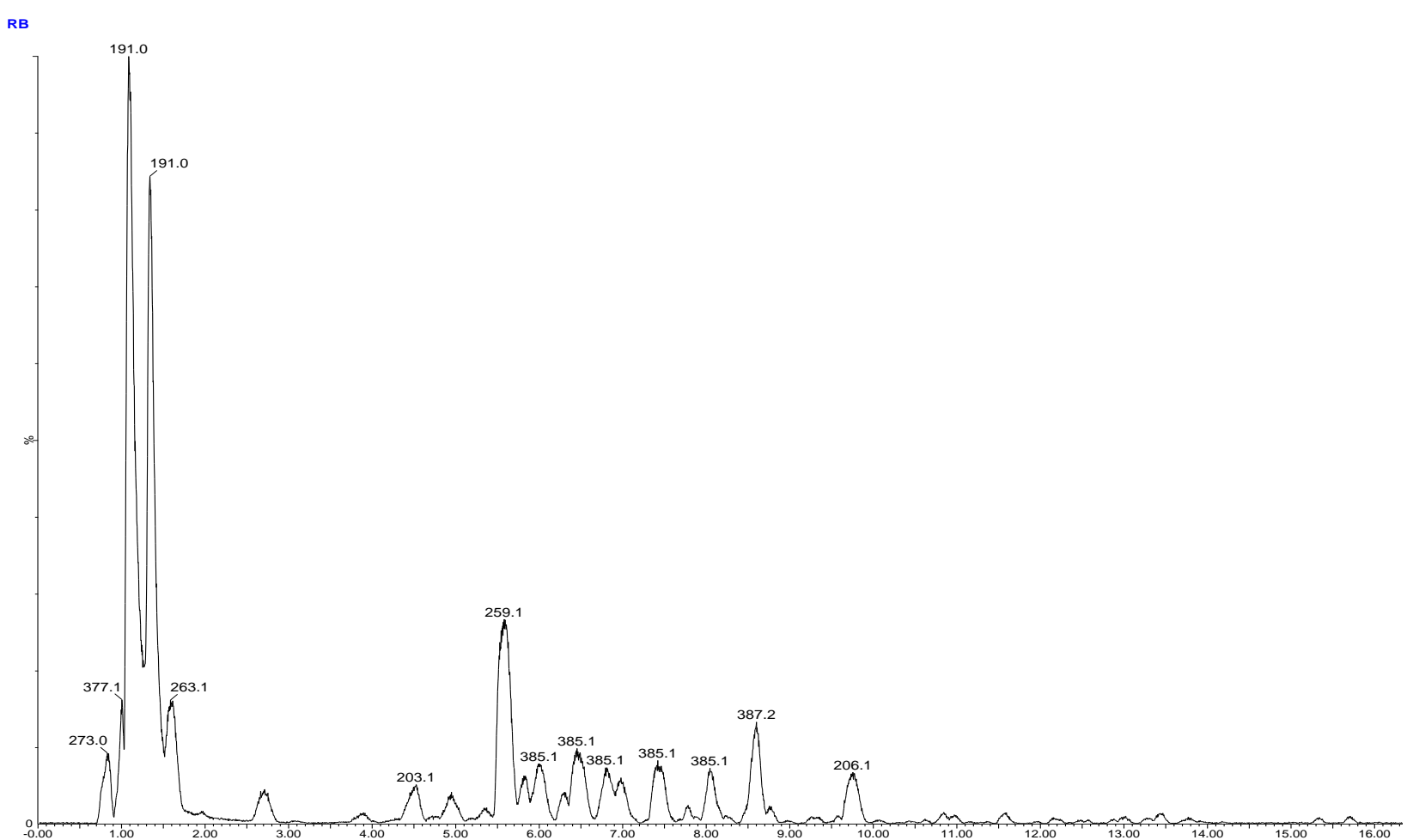

Figure 9. HPLC-PDA-ESI-MS chromatogram of $70 \%$ methanol extract of the uncooked red beans. Number on top of each peak is the $\mathrm{m} / \mathrm{z}$ of the deprotonated molecule $[\mathrm{M}-\mathrm{H}]^{-}$of each compound

Based on the literature data and fragmentation pattern, attempts were made to identify the new emerging compounds in both the cooked red beans and red bambara groundnuts. Some emergent compounds that were tentatively identified are presented in Tables 5 and 6 respectively. 
Table 5. Emerging phenolic compound tentatively identified in cooked red bambara groundnuts

\begin{tabular}{ccc}
\hline Parent ion [m/z] & Fragment ions [m/z] & Tentative identification \\
\hline 341 & 179,161 & Caffeic acid hexoside $^{\mathrm{v}}$ \\
305 & $289,263,247,219$ & Gallocatechin $^{\mathrm{w}}$ \\
389 & $185,157,143$ & Resveratrol glucoside $^{\mathrm{w}}$ \\
625 & $239,179,164$ & Caffeic acid derivative $^{\mathrm{x}}$ \\
\hline
\end{tabular}

${ }^{\mathrm{v}}$ Hassain et al., 2010, ${ }^{\mathrm{w}}$ Amandeep et al., 2010, ${ }^{\mathrm{x}}$ Rabaneda et al., 2003, ${ }^{\mathrm{x}}$ Gouveia and Castilho 2011

Table 6. Emerging phenolic compound tentatively identified in cooked red beans

\begin{tabular}{ccc}
\hline Parent ion [m/z] & Fragment ions [m/z] & Tentative identification \\
\hline 451 & 289 & Catechin glucoside $^{\mathrm{a}}$ \\
608 & 301 & Quercetin conjugate $^{\mathrm{b}}$ \\
463 & 301 & Quercetin-3-O-glucoside $^{\mathrm{b}}$ \\
447 & 287 & Kaempferol glucoside $^{\mathrm{b}}$ \\
\hline
\end{tabular}

${ }^{\mathrm{a}}$ Estrella et al., 2011, ${ }^{\mathrm{b}}$ Lin et al., 2008

\section{Discussion}

Cooking has displayed positive changes in the antioxidant activity and the polyphenol phytochemical profiles of both red beans and red bambara groundnuts. The increase in polyphenol concentration may be attributed to the release of bound polyphenols as a result of cooking process. Generally, complex polypenols have the ability to bind with other natural compounds within the cell. According to Harbaum (2007), cell wall bound phenolics are present as monomeric, dimeric, or oligomeric compounds which are esterified to the cell components (carbohydrates, lignin, pectin and proteins). These cell components may undergo various changes during the cooking process. For instance, proteins may undergo thermal denaturation in which a number of bonds are weakened and broken, resulting in the loss of the tertiary structure. The loss of protein structure affects the polyphenol-protein interaction and bound phenolic compounds may be released. On the other hand, long chain carbohydrates tend to break down into simple sugars when cooked while simple sugars may form syrups. These changes may affect carbohydrate-polyphenol interaction resulting in the release of bound phenolic compounds. The study by Akillioglu and Karakaya (2010) on the total polyphenol content of cooked common beans that were first soaked in water for 3 hours reported a $78 \%$ increase in total polyphenol content, which was higher compared to the increase that has been observed in the present study. This could be due to the differences in the methodology and the samples used. In our study, pretreatment by soaking the samples prior to cooking was not done. According to Akillioglu and Karakaya (2009), differences between total polyphenol content of the beans cooked without soaking and cooked after soaking in water may be due to the increase in the efficacy of the heat process to extract phenolic compounds from the food matrix.

Changes in the concentration of invidual phenolic compounds after cooking can be explained in two ways: firstly, the bound phenolics present are released during the heating process due to changes that take place to the components to which they bind. Secondly, phenolic compounds which exist as oligomers and polymers (condensed tannins or proanthocyanidins) may disintegrate to release different constitutive units when heated. According to Cheynier (2005), phenolic compounds are highly unstable and are rapidly transformed into various products when the plant cells are damaged (for instance, during processing). The large increase in the concentration of flavanols (catechin and epicatechin) after cooking as observed in this study supports the second assumption. Catechin, epicatechin, epigallocatechin and gallocatechin are the main monomeric units present in condensed tannins (Shadkami et al., 2009). Proanthocyanidins may occur as polymers containing as much as 50 catechin units (Wahle et al., 2010). HPLC-PDA-ESI-MS profiling of the extracts from the cooked seeds revealed ten and five new compounds in the cooked red bambara groundnuts and red beans respectively. In cooked red bambara groundnuts, new compounds tentatively identified include caffeic acid hexoside, gallocatechin, resveratrol glucoside and a caffeic acid derivative. New compounds tentatively identified in red beans include catechin glucoside, quercetin-3-O-glucoside, kaemferol glucoside and quercetin conjugate.

Thermal processes have a large influence on the availability of phenolic compounds in food regardless of the method used. Changes in the polyphenol content have been reported in other foods as a result of heating using other methods other than domestic boiling. Roasting of peanuts at $130{ }^{\circ} \mathrm{C}$ for $33 \mathrm{~min}$ caused an increase in the total polyphenol content (Yu et al., 2005); similar results are observed for cashew nuts when they were roasted 
using the same processing conditions (Chandrasekara and Shahidi, 2011). In apple juice processing, an increase in temperature from $40{ }^{\circ} \mathrm{C}$ to $70{ }^{\circ} \mathrm{C}$ caused increase of flavonoid content by $50 \%$ (Gerard and Roberts, 2004). According to the study by Fuleki and Ricardo-DaSilva (2003), pasteurization of grape juice increased the concentration of catechin and procyanidins in cold pressed juices. In these situations, an increase of temperature improves the extraction of phenolic compounds from foods. In other foods, thermal processes have been reported to decrease the content of phenolic compounds. Significant losses are noticed in tomato sauce pasteurized at 115 ${ }^{\circ} \mathrm{C}$ for 5 min (Valverdú-Queralt et al., 2011). A loss of $40 \%$ in total phenolic compounds was observed in strawberries pasteurized at $85 \mathrm{C}$ for 5 min (Hartman et al., 2008). It seems reasonable to assume that each type of food responds differently with regards to polyphenol stability when subjected to different thermal processes. This may be ascribed to the difference in the food matrix. The food matrix can act as a barrier to heat effect or induce the degradation polyphenols that exist as polymers and oligomers. It is very difficult to dissociate the thermal processing effect from the food matrix effects when discussing changes that occur due to thermal processing (Irina and Mohamed, 2012).

The antioxidant activities of both the cooked red beans and red bambara groundnuts were higher compared to the uncooked. The free radical scavenging speed increased 10-fold in the presence of methanolic extract from cooked red bambara groundnuts compared to uncooked. By contrast, there was a 20 -fold increase in the presence of the methanolic extract from cooked red beans compared to uncooked. This finding is of great significance because free radicals react very quickly and require equally fast-acting scavengers. Yet again, extracts from the cooked red beans had greater FRAP derived total antioxidant power compared to the uncooked. However, the FRAP values for the uncooked and cooked red bambara groundnuts were not significantly different. Changes in the antioxidant activities are positive and may be attributed to the increase in the concentrations of total polyphenols and individual phenolic compounds. Further, the increase in the speed of DPPH free radical scavenging reaction by the antioxidants in the cooked legumes may be attributed to the new emerging compounds. There is a possibility that the emergent compounds have good free radical scavenging abilities. An increase in the antioxidant activity of various foods subjected to thermal processes has been reported by many workers (Chandrasekara and Shahidi, 2011; Freeman et al., 2010; Hartman et al., 2008; Sharma and Gujral 2011). Emergent compounds can have antioxidant activity sometimes higher than the initial phenolic compounds (Buchner et al., 2006). Due to thermal processing, synergies between antioxidant compounds and the food matrix can occur resulting into enhanced antioxidant activity of polyphenolic compounds (Wang et al., 2011). Increase in the antioxidant acitivity of flavonoids has been reported in thermally treated food matrix (Freeman et al., 2010). It seems that products of degradation, which are assumed to be more reactive than the initial phenolic compound and the synergistic interaction between the antioxidant compounds and the food matrix are key factors that may be ascribed to the enhanced antioxidant activity of thermally processed foods in some cases.

\section{Conclusion}

The study has demonstrated that cooking has positive effects on the antioxidant activities and phenolic phytochemical profiles of common beans and bambara groundnuts. In both common beans and bambara groundnuts, antioxidant activities are higher in the cooked samples compared to the uncooked. Cooking favoured the release of phenolic compounds and subsequently resulted in high concentrations of total polyphenols and individual phenolic compounds. Additionally, HPLC-PDA-ESI-MS advanced analytical technique revealed that new phenolic compounds emerge after cooking, and these may have an additive effect on the antioxidant activities. New compounds tentatively identified in cooked red bambara groundnuts include caffeic acid hexoside, gallocatechin, resveratrol glucoside and a caffeic acid derivative. In cooked red beans, new compounds tentatively identified include catechin glucoside, quercetin-3-O-glucoside, kaempferol glucoside and a quercetin conjugate. Cooking therefore enhances the nutraceutical profiles in both common beans and bambara groundnuts.

\section{References}

Akıllığlu, G. H., \& Karakaya, S. (2009). Effect of Some Domestic Cooking Methods on Antioxidant Activity, Total Phenols and Total Flavonoid Content of Common Beans. Akademil Gida, 7(6), 6-12.

Akillioglu, G. H., \& Karakaya, S. (2010). Changes in Total Phenols, Total Flavonoids, and Antioxidant Activities of Common Beans and Pinto Beans after Soaking, Cooking, and in vitro Digestion Process. Food Sci. Biotechnol., 19(3), 633-639. http://dx.doi.org/10.1007/s10068-010-0089-8

Amandeep, K. sandhu, \& Liwei, G. (2010). Antioxidant Capacity, Phenolic Content, and Profiling of Phenolic Compounds in the Seeds, Skin, and Pulp of Vitis rotundifolia (Muscadine Grapes) As Determined by HPLC-DAD-ESI-MSn. J. Agric. Food Chem, 58, 4681-4692 4681. http://dx.doi.org/10.1021/jf904211q 
Becker, E. M., Nissen, L. R., \& Skibsted, L. H. (2004). Antioxidant evaluation protocols: Food quality or health effects. Eur. Food Res. Technol, 19, 561-571. http://dx.doi.org/10.1007/s00217-004-1012-4

Benzie, I. F. F. (1996). Clin. Biochem. 29, 111-116.

Buchner, N., Krumbein, A., Rhon, S., \& Kroth, L.W. (2006). Effect of thermal processing on the flavonol rutin and quercetin. Rapid Comm. in Mass Spectro., 20, 3229-3235. http://dx.doi.org/10.1002/rcm.2720

Chandrasekara, N., \& Shahidi, F. (2011). Effect of roasting on phenolic content and antioxidant activities of whole cashew nuts, kernels and testa. J. Agric. Food Chem, 59, 5006-5014. http://dx.doi.org/10.1021/jf2000772

Cheynier, V. (2005). Polyphenols in foods are more complex than often thought. Am. J. of Clin. Nutr. 81(suppl), 223S-9S.

Danesi (2009). PhD thesis Biological Effects of Bioactive Components and Extracts derived from Edible plants Commonly used in Human Nutrition. PhD thesis, University of Bologna

Estrella, I., Aguilera, Y. Benitez, V., Rosa, M. Esteban,. Martín-Cabrejas (2011). Bioactive phenolic compounds and functional properties of dehydrated beans flours. Food Res. Int. 44, 774-780. http://dx.doi.org/10.1016/j.foodres.2011.01.004

Freeman, B. L., Eggett, D. L., \& Parker, T. L. (2010). Synergistic and antagonistic interactions of phenolic compounds foung in navel oranges. J. Food Scie., 75(6), C570-C576. http://dx.doi.org/10.1111/j.1750-3841.2010.01717.x

Fuleki, T., \& Ricardo-Da-Silva, J. M. (2003). Effect of cultival and processing methods on the contents of catechin and procyanidins in grape juice. J. Agric. Food Chem, 51, 640-648. http://dx.doi.org/10.1021/jf020689m

Gerard, K. A., \& Roberts, J. S. (2004). Microwave heating of apple mash to improve juice yield and quality. Food Scie. and Techno., 37, 551-557. http://dx.doi.org/10.1016/j.lwt.2003.12.006

Gouveia S., \& Castilho P. C. (2011). Characterisation of phenolic acid derivatives and flavonoids from different morphological parts of Helichrysum obconicum by a RP-HPLC-DAD-ESI-MS ${ }^{\mathrm{n}}$ method. Food Chem, 129, 333-344. http://dx.doi.org/10.1016/j.foodchem.2011.04.078

Gülçin, E., Bursal, H. M., Sehitoglu, M., Bilsel, \& Gören, A. C. (2010). Polyphenol contents and antioxidant activity of lyophilized aqueous extract of propolis from Erzurum, Turkey. Food Chem. Toxicol, 48, 2227-2238. http://dx.doi.org/10.1016/j.fct.2010.05.053

Harbaum, B. (2007). Characterization of Free and Cell-Wall-Bound Phenolic Compounds in Chinese Brassica Vegetables. PhD thesis, Christian-Albrechts-Universität zu Kiel.

Hartmann, A., Patz, C. D. Andlauer, W., Dietrich, H., \& Ludwig, M. (2008). Influence of processing on quality parameters of strawberries. J.Agric. Food Chem, 56(20), 9484- 9489. http://dx.doi.org/10.1021/jf801555q

Hassain, M., Dilip K., Brunton, Nigel, Martin-Diana, A., \& Barry-Ryan, C. (2010). Characterization of Phenolic Composition in Lamiaceae Spices by LC-ESI-MS/MS. J. Agric. Food Chem, 58(19), 10576-10581. http://dx.doi.org/10.1021/jf102042g

Irina, I., \& Mohamed, G. (2012). Biological activitities and effects of food processing on flavonoids as phenolic antioxidants. Adv. in Appl. Biotechnol., ISBN: 978-953-307-820-5, In Tech. http://dx.doi.org/10.5772/30690

Kalt, W. (2005). Effects of Production and Processing Factors on Major Fruit and Vegetable Antioxidants. $J$ Food Sci 70(1), R11-R19. http://dx.doi.org/10.1111/j.1365-2621.2005.tb09053.x

Lin, L. Z., James, M. Harnly, Matcial, S. Pastor-Corrales, \& Devanand, L. (2008). The Polyphenolic profiles of common beans (Phaseolus vulgaris L.). Food Chem, 107, 399-410. http://dx.doi.org/10.1016/j.foodchem.2007.08.038

Makkar, H. P. S., Hagerman, A., \& Mueller-Harvey, I. (2000). Quantification of tannins in tree foliage - a laboratory manual, FAO/IAEA Working Document. IAEA, Vienna, 23-24.

Mitcham, B., Cantwell, M., \& Kader A. (1996). Methods for Determining Quality of Fresh Commoditites. Perishables Handling Newsletter, February Issue, 85, 1.

Nyau, V., Prakash, S., Rodrigues, J., Farrant, J. (2015). Antioxidant Activities of Bambara Groundnuts as Assessed by FRAP and DPPH Assays. Am. J. of Food and Nutr., 3(1), 7-11. 
http://dx.doi.org/10.12691/ajfn-3-1-2

Nyau, V., Prakash, S., Rodrigues, J., Farrant, J. (2016). Screening Different Zambian Market Classes of Common Beans (Phaseolus vulgaris) for Antioxidant Properties and Total Phenolic Profiles. J. of Food and Nutr. Res., 4(4), 230-236. http://dx.doi.org/10.12691/jfnr-4-4-6

Pal, D. K., Kumar, S., Chakraborty, P., \& Kumar, M. A. (2008). A study on the antioxidant activity of Semecarpus anacardium L. f. Nuts. J. of Nat. Rem., 8, 160-163.

Papas, A. (1996) Determinants of antioxidant status in humans. Lipids, 31(1) S77-S82. http://dx.doi.org/10.1007/BF02637055

Rabaneda, F. S., Olga, Ja'uregui, Rosa Maria Lamuela-Ravento Jaume Bastida, Francesc Viladomat \& Carles Codina. (2003). Identification of phenolic compounds in artichoke waste by high performance liquid chromatography-tandem mass spectrometry. J. of Chrom. A 1008, 57-72. http://dx.doi.org/10.1016/S0021-9673(03)00964-6

Shadkami, F., Estevez, S., \& Helleur, R. (2009). Analysis of catechins and condensed tannins by thermally assisted hydrolysis/methylation-GC/MS and by a novel two step methylation. J. of Analy. and Appl. Pyroly, 85, 54-65. http://dx.doi.org/10.1016/j.jaap.2008.09.001

Sharma, P., \& Gujral, H. S. (2011). Effect of sand roasting and microwave cooking on antioxidant activity of barley. Food Res. Int., 44, 235-240 http://dx.doi.org/10.1016/j.foodres.2010.10.030

Valverdú-Queralt, A., Medina-Remón, A., Andres-Lacueva, C., \& Lamuela-Raventos, R. M. (2011). Changes in phenolic profile and antioxidant activity during production of diced tomatoes. Food Chem., 126, 1700-1707. http://dx.doi.org/10.1016/j.foodchem.2010.12.061

Villaño, D., M. S. Fern’andez-Pach’on, M. S., M. L. Moy’a, M. L., Troncoso, A. M., \& Garc'ia-Parrilla, M. C. (2007). Radical scavenging ability of polyphenolic compounds towards free radicals. Talanta, 71, 230-235.

Wahle, K. W., Brown, I., Rotondo, D., \& Heys, S. D. (2010). Plant Phenolics in the Prevention and Treatment of Cancers. Adv. Exptl. Med. Biol. 698, 36-51. http://dx.doi.org/10.1007/978-1-4419-7347-4_4

Wang, S., Meckling, K. A., Marcone, M. F., Kakuda, Y., \& Tsao, R. (2011). Synergistic, additive, and antagonistic effects of food mixtures on total antioxidant capacities', J. Agric. Food Chem., 59, 960-968. http://dx.doi.org/10.1021/jf1040977

Waters Corporation (2002). HPLC troubleshooting guide. American Laboratory and Waters Corporation, 720000181EN, 08/02.

Yu, J., Ahmedna, M., \& Goktepe, I. (2005). Effects of processing methods and extraction solvents on concentration and antioxidant activity of peanut skin phenolic. Food Chem., 90, 199-206. http://dx.doi.org/10.1016/j.foodchem.2004.03.048

\section{Copyrights}

Copyright for this article is retained by the author(s), with first publication rights granted to the journal.

This is an open-access article distributed under the terms and conditions of the Creative Commons Attribution license (http://creativecommons.org/licenses/by/4.0/). 